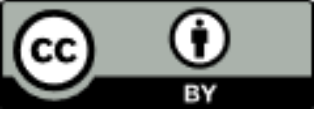

Ervin Kovačević

International University of Sarajevo
UDC 81'373.111=111

Original scientific article

Accepted for publication on 07.10 .2019

https://doi.org/10.29162/jez.2019.20

\title{
The relationship between lexical complexity measures and language learning beliefs
}

\begin{abstract}
Although the relationship between language proficiency and learner beliefs is generally viewed as weak, indirect, and distant, there are empirical findings which show that the relationship between syntactic complexity measures and language learning beliefs is statistically tangible. Since syntactic complexity is only one constituent of the linguistic complexity system, it seems plausible to question whether other constituents of the system are also in statistically measurable relationships with language learning beliefs. This research project explores the relationship between 25 lexical complexity measures ( $\mathrm{Lu}$ 2012; 2014) and four subscales of language learning beliefs that are suggested for Horwitz's (2013) Beliefs about Language Learning Inventory-BALLI 2.0 (Kovačević 2017). For three semesters (Fall 2014, Spring and Fall 2015), 152 freshman students at the International University of Sarajevo responded to BALLI 2.0 and wrote in-class exam essays which were converted into an electronic format. The results show 15 statistically significant correlation coefficients between 14 lexical complexity measures and three BALLI 2.0 subscales. Overall, it may be concluded that the relationship between lexical complexity measures and language learning beliefs is statistically detectable. The findings imply that the lexical complexity framework offers valuable opportunities for exploring how and to what extent particular individual differences manifest in foreign language production.
\end{abstract}

Key words: language learning beliefs; complexity; correlation; BALLI; corpora.

\section{Introduction}

Learners' varying levels of second language acquisition success can be partly ascribed to their individual differences (ID). This premise produced a large number 


\section{Ervin Kovačević: \\ The relationship between lexical complexity measures and language lear- ning beliefs}

of publications that question various links between second language production and ID variables such as age, personality, attitude, or aptitude (De Bot 2015; Dörnyei \& Ryan 2015). While research on the roles of ID variables in second language learning seemed to lose its momentum towards the end of the 1990s (De Bot 2015), the inconclusive nature of research outcomes kept attracting researchers' attention. One of the ID variables whose role in second language production may be described as only partly resolved is the construct of learner beliefs (Dörnyei \& Ryan 2015).

Kalaja \& Barcelos (2003: 1) broadly define learner beliefs as "opinions and ideas that learners (and teachers) have about the task of learning a second/foreign language". While Dörnyei (2005) doubts that learner beliefs are a proper ID variable because they may not be viewed as an enduring learner characteristic, Dörnyei \& Ryan (2015: 191) reassess the doubt and conclude that learner beliefs have the potential to become "the most versatile of all the learner characteristics" as they appear to be a complex ID feature that subsumes certain aspects of other individual traits such as motivation, self-regulation, and attitude.

The versatile nature of learner beliefs inspires ongoing research on their dynamics and their relationships with various factors that affect them. For example, Barcelos (2015) explores the relationship between learner beliefs and emotions and concludes that the relationship is dynamic and reciprocal. Aslan \& Thompson (2018) investigate the relationship between learner beliefs and anxiety and find that positive beliefs may reduce anxiety and improve linguistic confidence. Zhong (2013) analyzes the link between learner beliefs and learner autonomy and argues that some learner beliefs are conducive to learner autonomy. These research approaches and their outcomes significantly help our understanding of the nature of learner beliefs across various perspectives. On the other hand, research on the relationship between learner beliefs and foreign language proficiency remains scarce. Ellis (2008: 11) states that "there have to date been very few studies of the relationship between learner beliefs and learning outcomes".

Available studies which explore the link between learner beliefs and second language proficiency do so by relying on total proficiency scores (Mori 1999; Tanaka \& Ellis 2003) and categorizations of proficiencies into low, medium, and high (Yuen 2002; Jee 2017). Tanaka \& Ellis (2003) found weak negative correlations between "beliefs about analytic learning" and listening, reading, and the Test of English as a Foreign Language (TOEFL) scores. Mori (1999) found weak positive correlations between "beliefs about difficulty of a target language" and achievement. The same author also reports weak negative correlations between "beliefs about avoiding learning ambiguities" and students' proficiency. Yuen (2002) iden- 
tified ten learner beliefs that correlated positively with language proficiency and one belief that correlated negatively. Jee (2017) discovered weak positive correlations between the levels of perceived linguistic self-confidence and beliefs about motivation and expectations. Overall, the results suggest that learner beliefs play varying roles in second language production.

While these findings are founded on learner belief variables which depend on several learner belief taxonomies, e.g. Schommer's (1990) belief dimensions, Horwitz's $(1987 ; 1988)$ beliefs about language learning (BALLI) taxonomy, or unique factor analyses, their variables of linguistic output are represented by arbitrary proficiency scores and descriptions which disguise numerous elements of linguistic output. In other words, while beliefs are presented and examined in detailed ways, proficiency is explained in arbitrary categorizations. Unlike some studies which explore the relationships between language learning strategies and specific aspects of language production (Cooper \& Morain 1980; Cooper 1981; Fellner \& Apple 2006), studies which examine the links between learner beliefs and language output do not seem to attempt to identify potential links between special sets of learner beliefs and particular aspects of second or foreign language use.

It may be assumed that the demanding task of processing learner corpora plays a role in researchers' decisions to rely on arbitrary scores and categorizations of learner language output. Recent technological advances have provided practical tools that help researchers process large samples of learner corpora efficiently ( $\mathrm{Lu}$ 2014; Friginal et al. 2017). These tools are being utilized more and more frequently in language testing and assessment (Callies \& Götz 2015). Granger (2002) believes that utilizing these tools, together with the principles and methods developed in corpus linguistics since the late 1980s, may provide improved descriptions of learner language. Such descriptions can avoid arbitrary classifications that disguise particularities of learners' language output.

One way of describing language learners' proficiency in detail is by relying on the indices that measure language complexity features ( $L u$ 2014; Bulté \& Housen 2015). Using a computation program for automated corpus analysis (Lu 2014), Kovačević (2017) examines the link between language learning beliefs and complexity levels of learners' syntactic output, and identifies nine statistically significant weak and negative correlation coefficients between eight measures of syntactic complexity levels and two sets of language learning beliefs. However, these findings only point at the link between learner beliefs and syntactic aspects of second language production. Since lexical aspects of language complexity are equally im-

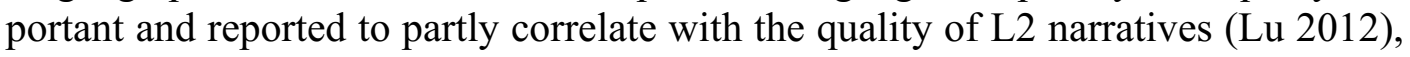




\section{Ervin Kovačević:}

The relationship between lexical complexity measures and language learning beliefs

and since there is no available research on the relationship between learner beliefs and measures of lexical complexity, the question of whether there is a link between learner beliefs and lexical output appears worthy of exploration.

The present study aims to identify whether lexical complexity measures and language learning beliefs are related. It originated from the following observations:

1. there is a limited number of studies about the relationship between learner beliefs and second/foreign language production;

2. the majority of available studies rely on total scores and arbitrary proficiency classifications and, therefore, do not provide information about specific aspects of language production that could be potentially explained by language learner beliefs and vice versa;

3. a number of syntactic complexity indices are found to be in negative correlation with language learning beliefs; these findings can be complemented by an examination of the link between learner beliefs and lexical complexity measures (which are found to correlate with L2 output).

The findings will inspire future researchers to recognize the need for exploring links between language complexity measures and ID variables. Such efforts can additionally describe the roles that ID variables play in language production together with various contextual factors and language instruction methodologies.

\section{Literature review}

\subsection{The relationship between language learning beliefs and language proficiency}

The role of learner beliefs in second language production is often described as indirect; beliefs are mediated through strategies and motivation levels and shaped by immediate and remote experiences (Barcelos 2003; Ellis 2008). Ellis (2008) acknowledges the reciprocal nature of the link between beliefs and experience/actions and explains that the role of beliefs in L2 learning/production may be proportional to the learner's will to self-reflect and act on individual beliefs. Several studies (Li 2010; Chang \& Shen 2010; Kovačević \& Akbarov 2016) report mainly moderate and weak positive correlation coefficients between language learning beliefs and language learning strategies, which may be described as mediators between beliefs and actions. 
Tanaka \& Ellis (2003) conducted a study on the changes of learner beliefs and proficiency levels in 166 Japanese university students who participated in a 15week study program in the U.S. They collected information about the students' learner beliefs by means of the Learner Belief Questionnaire. The Learner Belief Questionnaire was constructed by relying on several available learner belief taxonomies and a set of new survey items (cf. Tanaka \& Ellis 2003). The participants' language proficiency was diagnosed with a paper-based version of the TOEFL. It tested the participants' reading and listening comprehension and their ability to recognize correct grammar. The data was collected before the program began and towards the end of the program. The authors report statistically significant growth in proficiency in all three tested skills and a statistically significant increase in the levels of conviction across three types of learner beliefs. The correlation tests revealed statistically significant negative weak coefficients between the "Analytic Learning" factor and listening scores before the program experience, and almost identical coefficients between the same set of learner beliefs and reading scores after the program. On both occasions, the overall TOEFL score was found to be in statistically significant negative weak correlations with the "Analytic Learning" factor. Tanaka \& Ellis (2003) expected that the learners who held stronger beliefs about analytic learning (i.e. the learners who attached stronger importance to grammar, vocabulary, and a disciplined classroom) would do better in the exam. However, they dismissed the hypothesis and concluded that "the construct of 'language learning' that informed the learners' responses to the belief questionnaire was very different from the construct of 'language learning' that underlies the TOEFL" (Tanaka \& Ellis 2003: 80).

Mori (1999) explored the relationships between language learning beliefs and language proficiency/achievement with 187 university students enrolled in Japanese as a foreign language course. The language learning beliefs questionnaire comprised 42 items classified across six factors. Variables that indicated the learning outcomes consisted of daily quizzes, achievement exams, proficiency tests, and course achievement grades. The author reports four statistically significant weak positive correlation coefficients between the "Japanese is Easy" factor and learning outcomes, one very similar coefficient for the correlation between the "Analytic Approach" factor and course achievement, and one statistically significant weak negative correlation between the "Avoid Ambiguity" factor and achievement exam results. The findings imply that the learners who believe that the target language is easy, tolerate learning ambiguities, and rely on compensation resources, achieve partly better learning outcomes, and vice versa. However, it needs to be noted that Mori (1999) utilizes several language learning beliefs items in the factors titled 


\section{Ervin Kovačević:}

The relationship between lexical complexity measures and language learning beliefs

"Analytic Approach" and "Avoid Ambiguity" which resemble "language learning strategies"; language learning strategies are conceptualized as self-employed actions, rather than assumptions, which shape foreign language learning and use (Oxford 2013; Kovačević \& Akbarov 2016). For example, this is evident in Mori's (1999) questionnaire item 38 that states I try to avoid topics that I feel I cannot discuss well in Japanese and item 21 that states When studying kanji words, I try to think how each character is related to the meaning of the whole word.

Yuen (2002) studied the beliefs of 72 Hong Kong Chinese secondary school students and explored the relationship between their language learning beliefs and final oral examination results. The students' beliefs were collected with Horwitz's BALLI instrument $(1987 ; 1988)$. Their language proficiency results were classified across three categories, namely "students with high, medium, and low proficiency". The author identified ten language learning beliefs which are in a weak positive and one belief which was in a weak negative correlation with proficiency results. The survey items that correlated positively comprised the beliefs about personal language aptitude, importance of repetition and practice, guessing as a communication strategy, and appreciation of target language and culture. The survey item which explores whether learning English is mostly about translating was found to correlate negatively with proficiency. The results confirmed Mori's (1999) findings according to which it appears that the linear aspects of the relationship between language learning beliefs and language proficiency are embedded in the learner's perception of the challenge of the foreign language learning task and the learner's viewpoints on particular communication and learning strategies.

Jee (2017) explored beliefs about language learning in relation to perceived linguistic self-confidence with 156 learners of Korean as a foreign language in Australia. Jee utilized the BALLI developed by Horwitz $(1987 ; 1988)$ and the Perceived Linguistic Self-confidence (PLS) inventory (Pyun et al. 2014). Based on the PLS results, the learners were grouped as high, mid, and low PLS. Jee (2017) reports weak positive correlation coefficients between the total BALLI score and PLS levels. The author also reports similar coefficients for the correlation between the BALLI motivation and expectations factor and the PLS. These findings confirm Yuen's (2002) results according to which higher second language proficiency may be partly explained by a stronger appreciation of a target language and culture - i.e. the levels of motivation for and expectations from the target language learning.

The findings of these four studies may be summarized as follows:

1. the reported correlations between language learning beliefs and language proficiency are of weak magnitude; 
2. learner beliefs are in both statistically significant positive and negative correlations with language proficiency;

3. the beliefs about the ease of learning a target language, target culture appeal, and motivation correlate positively with language proficiency;

4. the beliefs about the positive roles of grammar, practice, disciplined classroom, learning through translation, and avoiding learning/communication ambiguities correlate negatively with language proficiency.

While these studies confirm that the relationship between learner beliefs and language proficiency is weak and dependent on belief types, they do not show how this relationship may be evident across detailed language production parameters and whether particular aspects of language production performance could be explained by learner beliefs. The following sections present the language complexity framework as an alternative to the overall scores and "high, mid, and weak" proficiency classifications.

\subsection{Language complexity}

Language complexity in second language acquisition studies is put forward as a valid metric approach that can describe L2 performance, indicate proficiency, and measure L2 development (Housen \& Kuiken 2009; Bulté \& Housen 2015). The approach is an outcome of a theoretical framework which views language as a complex adaptive system and language learning as a complex - i.e. dynamic - process (De Bot 2015). This framework recognizes the relationship between the target language and its use as a twofold system in which nonlinear and linear links between numerous factors are shaped by both predictable and unpredictable roles of personal, situational, contextual, and linguistic elements. In other words, viewing language as a dynamic, complex, and adaptive system justifies scientific efforts that examine networks made of supposedly unrelated components (Beckner et al. 2009). Therefore, empirical descriptions of the relationships between language output and ID variables, such as learner beliefs, appear to be worthy scientific endeavors whose results may identify hardly noticeable associations between language learning, generating, and using.

While the core of this approach to language studies is relatively easy to present, the task of describing linguistic units as more or less complex is not a straightforward process at all. To be able to measure and subsequently compare complexities of linguistic units, it is necessary to isolate linguistic subsystems under which linguistic units share linguistic attributes and whose complexities can be calculated. 


\section{Ervin Kovačević:}

The relationship between lexical complexity measures and language learning beliefs

These subsystems may be described from absolute and relative complexity viewpoints (Bulté \& Housen 2015). The absolute viewpoint is driven by theoretical frameworks that describe a system relying on available knowledge about the system (Miestamo 2006). More complex descriptions mean more complexity. For example, cross-linguistic examinations have proven that languages vary in their complexity (Nichols 2009). Nevertheless, this point of view leaves the system-user (i.e. language-user) out of its scope. The relative perspective includes the user and starts with the questions "complex to whom" and "why" (Miestamo 2006: 346). In other words, this perspective recognizes the roles of ID, contextual, and linguistic variables in language processing, but it also significantly relies on the formulas developed on the grounds of the absolute viewpoint.

\subsection{Lexical complexity and language proficiency}

In their review of L2 complexity studies, Bulté \& Housen (2015) highlight the dominance of the quantitative approach to the language complexity research construct. The approach involves various formulas according to which frequencies of particular linguistic units (e.g. types of lexical forms and grammatical forms) are calculated. The calculations shape the premise that "more varied and diverse" is more complex. This remark can be used for identifying the concept of lexical richness as an equivalent with the concept of lexical complexity. If lexical richness can be defined as "manifest in language (L2) use in terms of the sophistication and range of an L2 learner's productive vocabulary" (Lu 2012: 190; Wolfe-Quintero et al. 1998), then a broader definition may state that lexical complexity is a measurable quality of a lexical system.

$\mathrm{Lu}$ (2012) explores the relationship of lexical richness to the quality of ESL learners' oral narratives. The narratives were chosen from an English Corpus of Chinese Learners and rated by a group of English teachers. Although the author mainly avoids relying on the term lexical complexity, his research design is grounded in the lexical complexity theoretical framework. Besides, the author measures "lexical richness" with a computational system named Lexical Complexity Analyzer (LCA). The system offers 25 measures of lexical complexity that the author classifies as measures of lexical density (one measure), sophistication (five measures), and variation (19 measures) (cf. Table 1).

Lexical density, the ratio of the number of lexical words to the number of words, is found to be in nonsignificant correlations with holistic ratings of L2 writing and speaking (Linnarud 1986; Engber 1995; Lu 2012). Lu (2012) claims that the literature about the relationship between lexical sophistication, the proportion of the 
number of sophisticated words/word types to the total number of words/word types, and language proficiency provides mixed results. The author states that two transformed measures (CVS1 and VS2; cf. Table 1) were found to be in statistically significant weak positive combined correlations with the output. Lexical variation is defined as "the range of a learner's vocabulary as displayed in his or her language" ( $\mathrm{Lu} 2012:$ 192). Lu (2012) concludes that several conceptualizations of lexical variation are evident. The author explains that different measures yield different results. The author's analysis of the correlations between lexical variation measures and L2 oral performance highlights statistically significant weak positive correlations in the cases of NDW-50, CTTR, RTTR, AdvV, and ModV (cf. Table 1), among other measures.

\subsection{Lexical complexity and language learning beliefs}

Kovačević (2017) examines the relationship between language learning beliefs and syntactic complexity indices. The study shows that nine survey items which describe "the learner's willingness to engage in communication with both native and non-native English speakers" (Kovačević 2017: 459) are in statistically significant weak negative correlation with seven syntactic complexity indices. It also shows that eight survey items which describe "the learner's interpretation of the quality English learning ambiance and speaking performance" (Kovačević 2017: 459) are in statistically significant weak negative correlation with two syntactic complexity indices. The author speculates that "L2 learners who hold weaker language learning beliefs formulate more complex syntactic structures" (Kovačević 2017: 462). The conclusion is aligned with Tanaka \& Ellis's (2003) study in which proficiency scores were found to be in weak negative correlation with learner beliefs. However, it contradicts Yuen (2002) and Jee's (2017) studies according to which beliefs about motivation are found to be in weak positive correlation with proficiency.

As syntactic complexity indices are found to correlate with both language learning beliefs and lexical complexity measures (Kovačević 2018), it seems plausible to expect that there may be a statistically tangible relationship between lexical complexity measures and language learning beliefs as well. In this regard, it may be explored whether the same beliefs which were found to correlate with measures of syntactic complexity also correlate with lexical complexity measures. If they do, the direction of correlation may suggest the overall role of these types of beliefs. For example, if they are in a negative correlation, it will be reconfirmed that certain aspects of lower language complexity output may partly explain stronger motivation beliefs (e.g. enjoying communicating in a foreign language for the purpose of 
practice) and stronger orientation beliefs (e.g. opinions about particular ways of language learning). However, if these or other learner beliefs are found to be in positive correlations with lexical complexity indices, this may suggest that the relationship between language learning beliefs and proficiency is not only dependent on the types of learner beliefs but also on the peculiarities of linguistic output.

\subsection{Summary of literature review}

The studies that examine correlations between learner beliefs and language proficiency (Mori 1999; Yuen 2002; Tanaka \& Ellis 2003; Jee 2017) show limited numbers of statistically significant weak correlation coefficients. These coefficients are not aligned on the direction of the relationship; the direction is found to be both positive and negative and this variation appears to be dependent on the types of learner beliefs. Therefore, it seems that further research needs to be done on this matter. Furthermore, the fact that these studies mainly rely on arbitrary proficiency ratings conceals the distinctiveness of particular links between language learner beliefs and language production. It is recognized that particular sets of language learning beliefs could be partly explained by the features of learner language output. However, to date there has been little evidence to support this premise.

By relying on the language complexity framework, it may be possible to pinpoint specific connections between beliefs about the language learning process and features of language output. The attempt to examine this relationship by utilizing syntactic complexity measures (Kovačević 2017) shows that weaker motivational and orientational beliefs may partly explain the production of longer (more complex) syntactic forms and vice versa. These findings need to be validated by utilizing alternative language complexity parameters. Due to the reported statistically significant correlations between syntactic and lexical complexity indices (Ko-

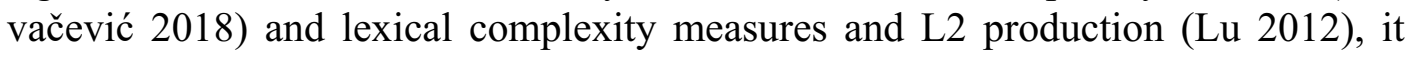
may be assumed that learner beliefs may be found to correlate with lexical complexity measures as well. If confirmed, the aforementioned premise could be further supported; this would mean that learner beliefs may partly explain and be partly explained by particular elements of linguistic output. While the magnitude of this correlation may be assumed to be weak, the direction of the correlation is hard to predict. This difficulty is not only generated by the mixed findings of the relevant studies but also by the broad range of language learning aspects embedded in learner beliefs, which explains why the findings about the relationship between learner beliefs and language proficiency vary. 


\subsection{Hypotheses}

Driven by correlational design principles, this research project examines the relationship between lexical complexity measures as suggested in $\mathrm{Lu}$ (2012) and language learning beliefs subscales as suggested for BALLI 2.0 (Horwitz 2013) in Kovačević (2017). The present study sets out to test the following hypotheses:

1. The measures of L2 users' lexical complexity output and the degrees of their language learning beliefs will correlate.

2. The magnitude of the correlations between the measures of L2 users' lexical complexity output and the degrees of their language learning beliefs will be weak.

3. The directions of the correlations between the measures of L2 users' lexical complexity output and the degrees of their language learning beliefs will vary across different measures of lexical output and subscales of language learning beliefs.

\section{Research method}

\subsection{Participants}

Bosnian undergraduate students at the International University of Sarajevo $(\mathrm{N}=152)$ produced the written corpus of essays for this study. Eighty-nine (89) female and sixty-three (63) male freshman students participated in the study. Twentyeight (28) of them studied at the Faculty of Arts and Social Sciences, twenty-five (25) at the Faculty of Business and Administration, and ninety-nine (99) at the Faculty of Engineering and Natural Sciences. All of the participants were found to be English-proficient (B2-C2) by the institutional language proficiency test held prior to enrollment in their undergraduate programs.

\subsection{Data collection procedure and instruments}

In Fall 2014, and Spring and Fall 2015 the participants were surveyed with the Beliefs About Language Learning Inventory/BALLI 2.0 (Horwitz 2013). Horwitz $(1985 ; 1987 ; 1988)$ developed the instrument that earned a reputation of the most widely used questionnaire for collecting data about language learning beliefs (Barcelos 2000: 45). The BALLI 2.0 is an updated version of the original instrument. It has 44 items, of which 41 items are Likert-type (strongly disagree, disagree, neu- 
tral, agree, strongly agree) and 3 multiple-choice items.

The instrument was published without subscales. Kovačević (2017) reports the results of factor and reliability tests that were done for the BALLI 2.0 and proposes deleting 18 items that lower the reliability of the instrument. When 18 items are deleted, a reliability analysis results in $\alpha=0.72$. The preserved 26 items are divided across 4 subscales with their arbitrary titles, reliability coefficients, factor loadings, and descriptions as follows:

1. The Motivation subscale $(\alpha=0.65 ; 0.35<x<0.59)$ describes the learner's motivation to engage in communication with English speakers (e.g. I enjoy practicing English with the people I meet).

2. The Orientation subscale $(\alpha=0.62 ; 0.39<x<0.59)$ describes the learner's understanding of an effective English learning setting and speaking performance (e.g. It is better to have teachers who are native speakers of English).

3. The Self-regulation subscale $(\alpha=0.47 ; 0.37<x<0.57)$ describes the learner's tendencies to favor particular aspects of the language learning/using process (e.g. It is easier to speak than understand English).

4. The Accuracy and Practice subscale $(\alpha=0.45 ; 0.49<x<0.59)$ describes the learner's perception of error-free speaking, their view on translation, and the utilization of different language skills (e.g. If beginning students are permitted to make errors in English, it will be difficult for them to speak correctly later on).

The lexical complexity measures were calculated for 152 English for Academic Purposes (EAP) essays. This EAP corpus was also utilized in Kovačević (2017). The paticipants wrote essays on general knowledge topics during in-class exams that did not allow utilizing any notes, dictionaries, and grammar books. The essays were converted to electronic formats and processed with the Web-based Lexical Complexity Analyzer (LCA) (Ai \& Lu 2010; Lu 2012, cf. Table 1). During the conversion, spelling errors were identified and corrected. 


\section{EZIKOSLOVLJE}

20.3 (2019): 555-582

Table 1. Measures of lexical density, sophistication, and variation calculated with LCA (Lu 2012)

\begin{tabular}{|c|c|c|}
\hline & Measure & Code \\
\hline Lexical Density & Lexical Density & LD \\
\hline \multirow{5}{*}{ Lexical Sophistication } & Lexical Sophistication-I & LS1 \\
\hline & Lexical Sophistication-II & LS2 \\
\hline & Verb Sophistication-I & VS1 \\
\hline & Corrected VS1 & CVS1 \\
\hline & Verb Sophistication-II & VS2 \\
\hline \multirow{19}{*}{ Lexical Variation } & Number of Different Words & NDW \\
\hline & NDW (first 50 words) & NDW-50 \\
\hline & NDW (expected random 50) & NDW-ER50 \\
\hline & NDW (expected sequence 50) & NDW-ES50 \\
\hline & Type-Token Ratio & TTR \\
\hline & Mean Segmental TTR (50) & MSTTR-50 \\
\hline & Corrected TTR & CTTR \\
\hline & Root TTR & RTTR \\
\hline & Bilogarithmic TTR & LogTTR \\
\hline & Uber Index & Uber \\
\hline & Lexical Word Variation & LV \\
\hline & Verb Variation-I & VV1 \\
\hline & Squared VV1 & SVV1 \\
\hline & Corrected VV1 & CVV1 \\
\hline & Verb Variation-II & VV2 \\
\hline & Noun Variation & NV \\
\hline & Adjective Variation & $\operatorname{Adj} \mathrm{V}$ \\
\hline & Adverb Variation & $\mathrm{AdvV}$ \\
\hline & Modifier Variation & ModV \\
\hline
\end{tabular}

$\mathrm{Lu}$ (2012) offers an extensive description of lexical complexity measures utilized in the present study, which can be summarized as follows:

- LD is the ratio of the number of lexical words to the number of words;

- LS1 is the ratio of the number of sophisticated lexical words to the total number of lexical words;

- LS2 is the ratio of the number of sophisticated word types to the total number of word types;

- VS1 is the ratio of the number of sophisticated verb types to the total number of verbs;

- CVS1 and VS2 are variations (corrections) of VS1 measure; 
- NDW, NDW-50, NDW-ER50, and NDW-ES50 measure the number of different words used in a language sample;

- TTR, MSTTR, CTTR, RTTR, LogTTR and the Uber Index indicate the ratio of the number of word types (T) to the number of words $(\mathrm{N})$ in a text;

- LV, VV1, SVV1, CVV1, VV2, NV, AdjV, AdvV, and ModV are the ways for calculating the variation of specific classes of words.

Although the measures of lexical density, sophistication, and variation may seem to overlap significantly, $\mathrm{Lu}$ (2012: 204) shows that they do not correlate strongly and therefore may be viewed as different constructs.

\subsection{Data analysis}

The correlations were calculated with the IBM SPSS Statistics 21 program. The data distribution was assessed with the Kolmogorov-Smirnov test, visual inspection of histograms, normal Q-Q plots, and box plots. The assessment of data distribution showed that a few variables were not normally distributed. As a result, the correlations between the variables were tested utilizing the Spearman's rank correlation coefficient.

\section{Results}

As can be seen in Table 2, our results confirm the hypotheses: lexical complexity measures and language learning beliefs are in statistically significant, weak both positive and negative correlations. In addition, Table 3 shows eight correlations whose $p$-values are above .05 but below .10. Although these coefficients are not statistically significant, their correlation magnitudes and directions are aligned with the statistically significant correlation coefficients presented in Table 2.

Out of 100 correlation coefficients (4 BALLI subscales x 25 LC measures), 15 correlation coefficients are statistically significant and eight correlation coefficients are almost statistically significant. Overall, this makes approximately one quarter of calculated coefficients that could show the relationship between language learning beliefs and lexical complexity measures as statistically tangible. 


\section{EZIKOSLOVLJE}

20.3 (2019): 555-582

Table 2. Statistically significant correlation coefficients betw. LC measures \& BALLI 2.0 subscales

\begin{tabular}{|c|c|c|c|c|}
\hline & & Motivation & Self-regulation & $\begin{array}{c}\text { Accuracy } \\
\text { and Practice }\end{array}$ \\
\hline \multirow{4}{*}{$\begin{array}{c}\text { Lexical } \\
\text { Sophistication }\end{array}$} & LS1 & $\mathrm{r}_{\mathrm{s}}=.181(\mathrm{p}=.026)$ & $\begin{array}{l}\mathrm{r}_{\mathrm{s}}=-.189 \\
(\mathrm{p}=.020)\end{array}$ & \\
\hline & VS1 & $\mathrm{r}_{\mathrm{s}}=.190(\mathrm{p}=.019)$ & & \\
\hline & VS2 & $\mathrm{r}_{\mathrm{s}}=.202(\mathrm{p}=.013)$ & & \\
\hline & CVS1 & $\mathrm{r}_{\mathrm{s}}=.203(\mathrm{p}=.012)$ & & \\
\hline \multirow{10}{*}{$\begin{array}{l}\text { Lexical } \\
\text { Variation }\end{array}$} & NDW & & & $\begin{array}{l}\mathrm{r}_{\mathrm{s}}=-.167 \\
(\mathrm{p}=.040)\end{array}$ \\
\hline & $\begin{array}{l}\text { NDW- } \\
\text { ER50 }\end{array}$ & & $\begin{array}{l}\mathrm{r}_{\mathrm{s}}=-.181 \\
(\mathrm{p}=.025)\end{array}$ & \\
\hline & $\begin{array}{l}\text { NDW- } \\
\text { ES50 }\end{array}$ & & $\begin{array}{l}\mathrm{r}_{\mathrm{s}}=-.194 \\
(\mathrm{p}=.017)\end{array}$ & \\
\hline & CTTR & & & $\begin{array}{l}\mathrm{r}_{\mathrm{s}}=-.165 \\
(\mathrm{p}=.043)\end{array}$ \\
\hline & RTTR & & & $\begin{array}{l}\mathrm{r}_{\mathrm{s}}=-.165 \\
(\mathrm{p}=.042)\end{array}$ \\
\hline & LV & & $\begin{array}{l}\mathrm{r}_{\mathrm{s}}=-.185 \\
(\mathrm{p}=.022)\end{array}$ & \\
\hline & VV1 & $\mathrm{r}_{\mathrm{s}}=.196(\mathrm{p}=.016)$ & & \\
\hline & SVV1 & $\mathrm{r}_{\mathrm{s}}=.196(\mathrm{p}=.016)$ & & \\
\hline & VV2 & $\mathrm{r}_{\mathrm{s}}=.164(\mathrm{p}=.044)$ & & \\
\hline & $\mathrm{AdvV}$ & & & $\begin{array}{l}\mathrm{r}_{\mathrm{s}}=-.162 \\
(\mathrm{p}=.047)\end{array}$ \\
\hline
\end{tabular}

Table 3. Correlation coefficients betw. LC measures \& BALLI subscales with p-values betw. 060 and .096

\begin{tabular}{|c|l|l|c|c|}
\hline \multirow{4}{*}{$\begin{array}{c}\text { Lexical } \\
\text { Sophistication }\end{array}$} & LS2 & Motivation & Self-regulation & $\begin{array}{c}\text { Accuracy } \\
\text { and Practice }\end{array}$ \\
\cline { 2 - 5 } & VS2 & & & \\
\cline { 2 - 5 } & CVS1 & & & $\begin{array}{c}\mathrm{r}_{\mathrm{s}}=-.136(\mathrm{p}=.094) \\
(\mathrm{p}=.088)\end{array}$ \\
\hline \multirow{5}{*}{$\begin{array}{c}\text { Lexical } \\
\text { Variation }\end{array}$} & NDW- & & & $\begin{array}{c}\mathrm{r}_{\mathrm{s}}=-.136 \\
(\mathrm{p}=.096)\end{array}$ \\
\cline { 2 - 5 } & ER50 & & & $\begin{array}{c}\mathrm{r}_{\mathrm{s}}=-.140 \\
(\mathrm{p}=.085)\end{array}$ \\
\cline { 2 - 5 } & ES50 & & & $\begin{array}{c}\mathrm{r}_{\mathrm{s}}=-.147 \\
(\mathrm{p}=.070)\end{array}$ \\
\cline { 2 - 5 } & UBER & & $\mathrm{r}_{\mathrm{s}}=-.153(\mathrm{p}=$ & $.060)$ \\
\cline { 2 - 5 } & VV1 & & & $\begin{array}{c}\mathrm{r}_{\mathrm{s}}=-.145 \\
(\mathrm{p}=.076)\end{array}$ \\
\cline { 2 - 5 } & SVV1 & & & $\mathrm{r}_{\mathrm{s}}=-.145(\mathrm{p}=$ \\
& & & $.074)$ \\
\hline
\end{tabular}



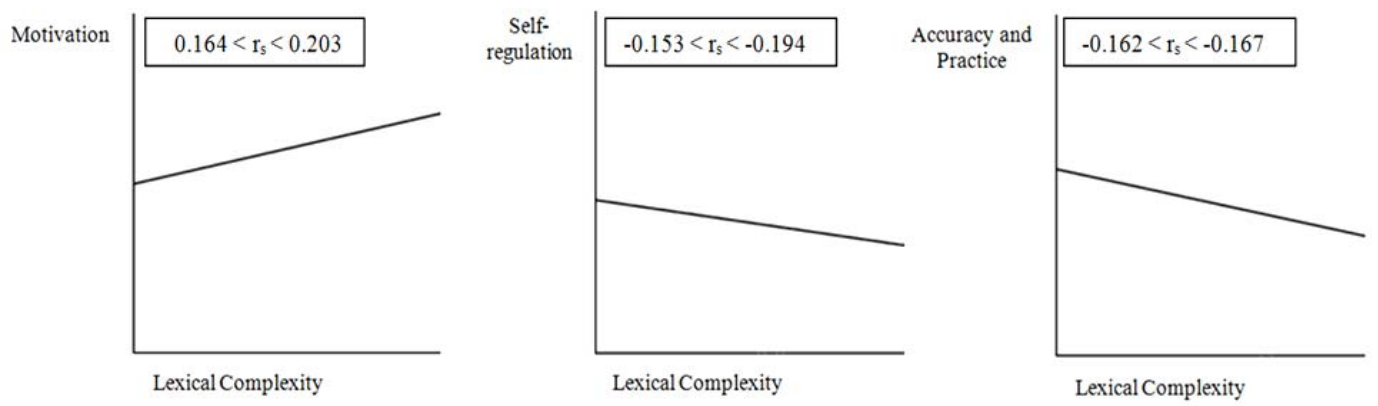

Figure 2. Magnitude and direction of statistically significant correlations between BALLI 2.0 subscales and lexical complexity measures as approximated with fit lines

Figure 2 summarizes the directions and magnitudes of the correlation coefficients and illustrates that beliefs about motivation are in positive and beliefs about selfregulation and accuracy and practice are in negative correlation with lexical complexity measures. In other words, the correlation test shows five key findings:

1. Stronger/weaker beliefs about motivation may partly explain certain aspects of higher/lower lexical complexity performance, and vice versa;

2. Stronger beliefs about self-regulation may partly explain certain aspects of lower lexical complexity performance, and vice versa;

3. Weaker beliefs about self-regulation may partly explain certain aspects of higher lexical complexity performance, and vice versa;

4. Stronger beliefs about accuracy and practice may partly explain certain aspects of lower lexical complexity performance, and vice versa.

5. Weaker beliefs about accuracy and practice may partly explain certain aspects of higher lexical complexity performance, and vice versa.

\section{Discussion}

The three hypotheses tested in this study have been confirmed:

1. the measures of second language users' lexical complexity output and the degrees of their language learning beliefs correlate;

2. the magnitude of the correlations is weak;

3. the directions of the correlations vary across different measures of lexical output and subscales of language learning beliefs. 
Hypothesis 1 was based on previous findings according to which language learning beliefs were found to correlate with levels of language proficiency (Mori 1999; Yuen 2002; Tanaka \& Ellis 2003; Jee 2017) and indices of syntactic complexity (Kovačević 2017). It was assumed that language learning beliefs would correlate with the measures of lexical complexity as well because lexical complexity measures were also found to correlate with L2 spoken output ratings (Lu 2012). The hypothesis was confirmed. While the findings of this study are aligned with the previously published results, they provide new evidence that language learning beliefs are not only linked to second language production through associations with the overall levels of second language proficiency, performances in reading and listening tests, or certain syntactic aspects of written output, but they are also related to particular lexical aspects of writing performance.

As pointed out earlier, learner beliefs subsume and partly overlap with several research constructs such as attitude, motivation, and self-regulation. It can be argued that language learning beliefs are byproducts of a bidirectional, self-regulated exchange between language learning/using experiences and motivational factors. These byproducts may manifest as abandoned, reinstated, or newly acquired assumptions about language learning processes. Therefore, explorations of the relationship between learner beliefs and language production cannot avoid examining the role of mediators such as motivation or language learning strategies, which are more likely to be directly or closely associated with language learning outcomes. In this regard, language performances and learner beliefs are in a reciprocal relationship that may be more and less evident when the links between specific elements of language performances and learner beliefs are examined. The confirmation of hypothesis 1 in this study shows that the relationship between language learning beliefs and language production may be evident in some aspects of the lexical richness of second language learners' written output. On the other hand, pending further research, this conclusion should only be interpreted through the prism of the findings reported in this study.

Hypothesis 2 was based on previous research which reported limited numbers of statistically significant weak correlation coefficients between language learning beliefs and second language proficiency (Mori 1999; Yuen 2002; Tanaka \& Ellis 2003; Jee 2017; Kovačević 2017). Moreover, anticipating moderate or strong correlation coefficients between learner beliefs and language outcomes would be overenthusiastic and would overlook the complex nature of various aspects of language; it would be an act of underestimating a long list of variables which were found to play highly specific and important roles in language learning and production (Beckner et al. 2009; Dörnyei \& Ryan 2015; Menn 2017). Therefore, if learner be- 


\section{Ervin Kovačević:}

The relationship between lexical complexity measures and language learning beliefs

liefs play any significant role in language production, this role can only be of a limited magnitude. The magnitude of statistically significant correlation coefficients reported in this study varies between -.162 and .203, which implies that the reciprocity between language learning beliefs and lexical complexity measures is conditioned by other, or many other variables which carry features of dynamic systems such as motivation (Dörnyei \& Ryan 2015), self-regulation (Oxford 2013), or anxiety (Aslan \& Thompson 2018). The implication may be supported by a close examination of individual learner belief items utilized in this study, which were found to be in statistically significant correlations with lexical complexity measures.

The Motivation BALLI 2.0 subscale was found to correlate with seven measures of lexical complexity, which is consistent with the reports of statistically significant weak correlations between the "motivation and expectations" BALLI subscale (Horwitz 1987; 1988) and levels of perceived linguistic self-confidence (Jee 2017) and proficiency levels (Yuen 2002). The Motivation BALLI 2.0 subscale comprises nine statements that question the learner's motivation and willingness to master and communicate in English (e.g. I want to speak English well; If I learn to speak English very well, I will have better opportunities for a good job; I would like to have English-speaking friends). These items embed motivational elements which may suggest that it is levels of motivation and willingness to engage in communication via second language rather than beliefs that need to be associated with levels of production. While this cannot be completely dismissed, it can be argued that motivation is in dynamic relationships with various elements generated by sociocultural, psychological, and contextual elements. Such elements rest upon particular goals and values attributed to benefits of L2 mastery and ways towards it (Gardner \& MacIntyre 1993). If language learner beliefs are conceptualized as opinions/ideas about aspects of L2 learning and teaching processes, then motivation may be seen as an aspect of learner beliefs that incorporates various forms of fully or partly resolved self-reflections. Since L2 learning outcomes are frequently associated with motivational levels (Dörnyei \& Ryan 2015), it may be plausible to conclude that there is indeed a weak link between motivational beliefs and language learning production.

The correlation coefficients between the Self-regulation BALLI 2.0 subscale and lexical complexity measures show that beliefs about particular aspects of L2 learning and usage (such as importance of knowledge about L2 culture, selfefficacy in learning L2 languages, or difficulty of particular L2 skills) may partly explain certain aspects of L2 lexical production. This finding is aligned with Mori's (1999) study according to which learner beliefs about the difficulty of a language, learning ambiguities, and relying on particular communication strategies are asso- 
ciated with language proficiency. Mori (1999) utilized a number of survey items whose content overlaps with the concept of language learning strategies (i.e. learning and communication actions) (e.g. I try to avoid topics that I feel I cannot discuss well in Japanese). The Self-regulation BALLI 2.0 subscale also comprises items such as It is necessary to know about English-speaking cultures in order to speak English and I have to spend so much time preparing for big English tests, that I do not have time to actually learn English, which suggest features of language learning strategies. These items imply the values embedded in strategies such as I try to learn about the culture of English speakers (a social strategy) and I plan my schedule so I will have enough time to study English (a metacognitive strategy) (cf. Oxford 1990). Since numerous studies report positive, statistically significant, mainly weak and some moderate correlations between language learning strategies and L2 proficiencies (Oxford 1999; Hsiao \& Oxford 2002), it may be assumed that learner beliefs which embed elements of language learning strategies are indeed partly related to certain aspects of language production. As is the case with motivational beliefs, self-regulation/strategy beliefs may be falsely dismissed as direct stakeholders in particular aspects of language production. However, due to the nature of their entanglement with strategies, they can and need to be perceived as counterparts of language learning outcomes that are mediated across elements of strategic reasoning.

The Accuracy and Practice BALLI 2.0 subscale comprises items which elicit data about benefits of translation, importance of accurate language usage, and perception of reading and writing as skills less challenging than speaking and writing. These beliefs were found to correlate with four measures of lexical variation. This finding is partly aligned with Tanaka \& Ellis's (2003) study where beliefs about grammar, practice, and disciplined classroom were found to correlate with listening, reading, and overall TOEFL scores, and Yuen's (2002) finding according to which beliefs about the role of translation correlate with proficiency levels. The Accuracy and Practice BALLI 2.0 items such as You shouldn't say anything in English until you can say it correctly or If beginning students are permitted to make errors in English, it will be difficult for them to speak correctly later on embed values which connote idealized features of L2 performance. Though it may seem a little bit farfetched, it may be speculated that error-free performances are fueled by universal maxims of communication that disallow ambiguities. Aslan \& Thompson (2018) find that fear of ambiguity is linked to classroom performance anxiety and that positive beliefs reduce anxiety and provide confidence in language learning. Therefore, the correlation between this learner belief subscale and measures of lexical variation may be partly resting on the links between L2 mastery 
Ervin Kovačević:

The relationship between lexical complexity measures and language learning beliefs

and the degrees of anxiety and confidence.

While the aforementioned three types of learner beliefs correlate weakly with certain aspects of lexical output, the Orientation BALLI 2.0 subscale was not found to correlate with any lexical complexity measures. This scale collects the data about learners' agreement with assumptions such as It is important to speak English like a native speaker or It is best to learn English in an English speaking country. These assumptions attempt to describe to what extent learners prefer native-like L2 proficiency, native L2 teachers, and authentic L2 ambiance. This scale was reported to weakly correlate with the ratios of dependent clauses per T-unit and dependent clauses per clause, two measures of syntactic complexity (Kovačević 2017). It may be argued that this type of beliefs is hard to expect to correlate with any language production parameter, and that its correlation with two syntactic complexity indices needs further verification. Unlike motivation, strategies, or anxiety, which were described as ID variables that affect learning outcomes (Dörnyei \& Ryan 2015), the appreciation of native L2 teachers and native-like L2 accent seems to be based on generally spread unwritten norms and thus difficult to link to language performance. Perhaps the previously identified correlations between this subscale and two indices of syntactic complexity may be explained by the negative direction of the reported coefficients; as levels of language proficiency increase, particular language learning beliefs weaken. This conclusion can be challenged as it is not valid for every type of learner belief; the directions of the reported correlations in the present and referenced studies reveal mixed characteristics. Overall, it is the directions which may yield crucial information about the relationship between learner beliefs and $\mathrm{L} 2$ production.

Hypothesis 3 assumed that the directions of correlations would vary across different types of learner beliefs and lexical complexity measures, and it was confirmed. Additionally, the measures of lexical sophistication and variation were found to be in positive correlation with the Motivation and in negative correlation with the Self-regulation subscale. The measures of lexical variation were found to be in negative correlations with the Accuracy and Practice subscale. The measure of lexical density was found not to correlate with any BALLI 2.0 subscales.

Four measures of lexical sophistication (LS1, VS1, VS2, and CVS1) and three measures of lexical variation (VV1, SVV1, VV2) were found to correlate positively with motivational beliefs. This means that the degree of willingness to speak to friends and strangers in L2 and the degree of determination to improve L2 are in part directly proportional to the frequency of utilizing more sophisticated lexical words (LS1), sophisticated word types (LS2), sophisticated verb types (VS1 and 
CVS1), and total verb types (VV1, SVV1, VV2). This finding is partly aligned with Yuen (2002) and Jee's (2017) findings, according to which beliefs about motivation and expectations are in part directly proportional to proficiency levels. However, it contradicts Kovačević's (2017) finding according to which beliefs about motivation are in part inversely proportional to the indices of syntactic complexity. This contradiction may be interpreted with an assumption that lexically more proficient L2 users generate shorter/less complex syntactic formulations when they are able to compress intended messages through more sophisticated lexical alternatives. Therefore, it may be concluded that the relationship between a single type of learner beliefs and language proficiency manifests differently across specific aspects of language output.

One measure of lexical sophistication (LS1) and three measures of lexical variation (NDW-ER50, NDW-ES50, and LV) were found to be in negative correlation with the beliefs about self-regulation. This finding implies that the degree of beliefs about certain aspects of the language learning process, such as learning about L2 grammar and finding speaking easier than understanding, is in inverse relationship with the frequency of production of sophisticated lexical words (LS1), the ratio of the number of word types to the number of words (NDW-ER50, NDW-ES50), and the level of lexical word variation (LV). This finding partly aligns with the reports of negative correlation between the beliefs about the role of grammar (Tanaka \& Ellis 2003), beliefs about avoiding ambiguities (Mori 1999) and language proficiency. Overall, the finding implies that stronger beliefs about particular aspects of language learning/using process may be founded on misassumptions about the role of some factors in L2 learning process. As L2 experience accumulates, some beliefs may lose their strength. This perhaps explains why lexically more proficient L2 users may hold partly weaker beliefs about learning. This is also evident in the relationship between measures of lexical variation and the Accuracy and Practice BALLI 2.0 subscale.

Four measures of lexical variation (NDW, CTTR, RTTR, and AdvV) were found to be in negative correlation with the beliefs about translation, accuracy, and practice. This finding partly matches Yuen's (2002) identification of negative correlation between the beliefs about translation and proficiency levels. It needs to be noted that thirteen measures of lexical variation were reported to be in combined positive correlations with spoken L2 output (Lu 2012). Therefore, it may be argued, as is case with the beliefs about self-regulation, that lexically more proficient L2 users hold weaker beliefs about the importance of particular beliefs specified in BALLI and similar surveys. Some authors suggested alternative ways for collecting data about learner beliefs. The argument is that surveys fail to capture the breadth 


\section{Ervin Kovačević:}

The relationship between lexical complexity measures and language learning beliefs

of assumptions and opinions held about the language learning process (Barcelos 2003). Regardless of methodological shortcomings, the relationship between learner beliefs and L2 production seems to be evident in the correlations between 14 measures of lexical complexity and three types of learner beliefs.

The measure of lexical density (LD) was not found to correlate with any of the belief variables. LD identifies the proportion of the number of lexical words to the overall number of words and was reported not correlate with L2 performance ( $\mathrm{Lu}$ 2012). It may be speculated that this measure may only significantly oscillate across highly different levels of L2 proficiency, but it is recognized that this assumption needs empirical evidence. Lu (2012) reports that this measure may significantly vary when compared across spoken and written L2 samples. It may be argued that LD is dependent on the absolute dynamics of a language system and therefore is hardly related to any ID variable.

\section{Conclusion}

This study reveals that the relationship between language learning beliefs and L2 production manifests in statistically significant weak correlations between different types of language learning beliefs and lexical complexity measures. Considering the intricate nature of language systems, both absolute and relative, the identified magnitude seems plausible; this relationship appears to be conditioned by a vast network of language and ID variables.

Drawing on the characteristics of the belief subscales utilized in this study, it may be concluded that language learning beliefs are related to L2 production across the connections facilitated by levels of L2 mastery, motivation, self-regulation, anxiety, and confidence. Although this conclusion may discredit the learner belief construct, it needs to be noted that language learning beliefs bring together several ID variables and offer opportunities for understanding how different components of an ID set may be simultaneously related to L2 performance. It is recognized that further examinations of the link between learner beliefs and L2 production may give this research construct a new momentum and perhaps help assert and cement its status of, as Dörnyei \& Ryan (2015: 191) put it, "the most versatile of all the learner characteristics".

The present study provides evidence that describing language proficiencies with language complexity measures is a valid way of identifying certain aspects of L2 performance that may be empirically associated with seemingly unrelated factors. However, the fact that statistically significant correlations can vary in directions 
implies that any attempt of describing the relationship between language learning beliefs and L2 performance depends to a high extent on the types of variables utilized. Therefore, it is recognized that new scales of language learning beliefs may provide grounds for identifying new associations between learner beliefs and L2 production. The same is true for the descriptions of L2 proficiency; alternative ways of calculating certain aspects of L2 performance may reveal different results.

It needs to be noted that the results of this analysis are produced on the basis of the learner corpus composed of essays produced by EAP users of Bosnian L1 background. Considering the relative nature of the linguistic complexity phenomenon, it may be assumed that utilizing English learner corpora from second language users of other L1 backgrounds could produce different results in a research design that explores the relationship between lexical complexity measures and language learning beliefs. Based on the findings and arguments presented in this study, it is unlikely that any correlation test could reveal any moderate or strong correlation coefficients; statistically significant results, if any, would probably be confirmed to be weak. What could vary is the nature of variables that are found to correlate.

It could also be interesting to examine the relationship between language complexity indices calculated on the basis of a spoken L2 output and learner beliefs. Considering the discrepancies between the results reported for the correlations between learner beliefs and syntactic complexity measures and learner beliefs and lexical complexity measures, it would be prudent, for purposes of such research, to utilize both syntactic and lexical complexity frameworks as variables of L2 speaking performance.

This study utilized two language learning subscales of relatively low reliability values. While the results seem to be aligned with the previously published findings, it may be argued that more reliable scales would generate different results. It is recognized that further research is necessary for validating the overall number of lexical complexity measures which correlate with language learning beliefs.

The learner corpus utilized in this study was generated by a compilation of EAP essays written about general knowledge topics during in-class exams. However, these essays were written on a number of different topics. It may be speculated that a single topic could provide a more valid sample with which lexical complexity measures could be calculated. 


\section{Ervin Kovačević: \\ The relationship between lexical complexity measures and language lear- ning beliefs}

\section{References}

Ai, Haiyang \& Lu, Xiaofei. 2010. A web-based system for automatic measurement of lexical complexity. (Paper presented at the 27th Annual Symposium of the ComputerAssisted Language Consortium (CALICO-10), Amherst, 8-12 June 2010.

Aslan, Erhan \& Thompson, Amy Suzanne. 2018. The interplay between learner beliefs and foreign language anxiety: Insights from the Turkish EFL context. The Language Learning Journal 1-14. https://doi.org/10.1080/09571736.2018.1540649

Barcelos, Ana Maria Ferreira. 2000. Understanding teachers' and students' language learning beliefs in experience: A Deweyan approach. Unpublished doctoral dissertation. Tuscaloosa: The University of Alabama.

Barcelos, Ana Maria Ferreira. 2003. Researching beliefs about SLA: A critical review. In Kalaja, Paula \& Barcelos, Ana Maria Ferreira (eds.), Beliefs about SLA: New research approaches, 7-33. New York: Springer.

Barcelos, Ana Maria Ferreira. 2015. Unveiling the relationship between language learning beliefs, emotions, and identities. Studies in Second Language Learning and Teaching 5(2). 301-325. https://doi.org/10.14746/ssllt.2015.5.2.6

Beckner, Clay \& Ellis, C. Nick \& Blythe, Richard \& Holland, John \& Bybee, Joan \& Ke, Jinyun \& Christiansen, H. Morten \& Larsen-Freeman, Diane \& Croft, William \& Schoenemann, Tom. 2009. Language is a complex adaptive system: Position paper. Language Learning 59 (Suppl. 1). 1-26. https://doi.org/10.1111/j.14679922.2009.00533.x

Bulté, Bram \& Housen, Alex. 2015. Evaluating short-term changes in L2 complexity development. Círculo de Lingüística Aplicada a la Comunicación 63. 42-76. doi: 10.5209/rev_CLAC.2015.v63.50169

Callies, Marcus \& Götz, Sandra. 2015. Learner corpora in language testing and assessment: Prospects and challenges. In Callies, Marcus \& Götz, Sandra (eds.), Learner corpora in language testing and assessment, 1-9. Amsterdam: John Benjamins.

Chang, Ching-yi \& Shen, Ming-chang. 2010. The effects of beliefs about language learning and learning strategy use of junior high school EFL learners in remote districts. $R e-$ search in Higher Education Journal 8. 1-8.

Cooper, C. Thomas \& Morain, Genelle. 1980. A study of sentence-combining techniques for developing written and oral fluency in French. The French Review 53(3). 411-423.

Cooper, C. Thomas. 1981. Sentence combining: An experiment in teaching writing. The Modern Language Journal 65(2). 158-165. https://doi.org/10.1111/j.15404781.1981.tb00967.x

De Bot, Kees. 2015. A history of applied linguistics. New York: Routledge.

Dörnyei, Zoltán. 2005. The psychology of the language learner: Individual differences in second language acquisition. Mahwah: Lawrence Erlbaum Associates. 
Dörnyei, Zoltán \& Ryan, Stephen. 2015. The psychology of the English learner revisited. New York: Routledge.

Ellis, Rod. 2008. Learner beliefs and language learning. The Asian EFL Journal Quarterly 10(4). 7-25.

Engber, A. Cheryl. 1995. The relationship of lexical proficiency to the quality of ESL compositions. Journal of Second Language Writing 4. 139-155. https://doi.org/10.1016/1060-3743(95)90004-7

Fellner, Terry \& Apple, Matthew. 2006. Developing writing fluency and lexical complexity with blogs. The JALT CALL Journal 2(1). 15-26.

Friginal, Eric \& Lee, J. Joseph \& Polat, Brittany \& Roberson, Audrey. 2017. Exploring spoken English learner language using corpora: Learner talk. Cham: Palgrave Macmillan. doi: 10.1007/978-3-319-59900-7

Gardner, C. Robert \& MacIntyre D. Peter. 1993. A student's contributions to secondlanguage learning. Part II: Affective variables. Language Teaching 26. 1-11. https://doi.org/10.1017/S0261444800000045

Granger, Sylviane. 2002. A Bird's-eye view of learner corpus research. In Granger, Sylviane \& Hung, Joseph \& Petch-Tyson, Stephanie (eds.), Computer learner corpora, second language acquisition, and foreign language teaching, 3-33. Amsterdam: John Benjamins Publishing. https://doi.org/10.1075/11lt.6

Horwitz, K. Elaine. 1985. Using student beliefs about language learning and teaching in the foreign language methods course. Foreign Language Annals 18. 333-340. https://doi.org/10.1111/j.1944-9720.1985.tb01811.x

Horwitz, K. Elaine. 1987. Surveying student beliefs about language learning. In Wenden, Anita \& Rubin, Joan (eds.), Learner strategies in language learning, 119-129. Hemel Hempstead: Prentice Hall.

Horwitz, K. Elaine. 1988. The beliefs about language learning of beginning foreign language students. Modern Language Journal 72(3). 283-294. https://doi.org/10.1111/j.1540-4781.1988.tb04190.x

Horwitz, K. Elaine. 2013. Becoming a language teacher. Upper Saddle River: Pearson.

Housen, Alex \& Kuiken, Folkert. 2009. Complexity, accuracy and fluency in second language acquisition. Applied Linguistics 30(4). 461-473. https://doi.org/10.1093/applin/amp048

Hsiao, Tsung-Yuan \& Oxford, L. Rebecca. 2002. Comparing theories of language learning strategies: A confirmatory factor analysis. The Modern Language Journal 86(3). 368383. https://doi.org/10.1111/1540-4781.00155

Jee, Min Jung. 2017. Examining beliefs about language learning in relation to perceived linguistic self-confidence: Learners of Korean as a foreign language in Australia. Linguistic Research 34. 25-48. https://doi.org/10.17250/khisli.34..201709.002

Kalaja, Paula \& Barcelos, Ana Maria Ferreira (eds.). 2003. Beliefs about SLA: New re- 
search approaches. New York: Springer. doi: 10.1007/978-1-4020-4751-0

Kovačević, Ervin \& Akbarov, Azamat. 2016. Language learning beliefs and strategies. Epiphany: Journal of Transdisciplinary Studies 8(3). 74-87. http://dx.doi.org/10.21533/epiphany.v8i3.178

Kovačević, Ervin. 2017. The relationship between language learning beliefs and syntactic complexity. In Gudurić, Snežana \& Radić-Bojanić, Biljana (eds.), Jezici i Kulture u Vremenu i Prostoru 6, 455-464. Novi Sad: University of Novi Sad.

Kovačević, Ervin. 2018. The relationship between lexical and syntactic complexity measures in a learner corpus. In Gudurić, Snežana \& Radić-Bojanić, Biljana (eds.), Jezici i Kulture u Vremenu i Prostoru 7, 469-479. Novi Sad: University of Novi Sad.

Li, Fenfang. 2010. Relationship between EFL learners' belief and learning strategy use by English majors in vocational colleges. Journal of Language Teaching and Research 6. 858-866. doi:10.4304/j1tr.1.6.858-866

Linnarud, Moira. 1986. Lexis in composition: A performance analysis of Swedish learners' written English. Lund: Gleerup.

Lu, Xiaofei. 2012. The relationship of lexical richness to the quality of ESL learners' oral narratives. The Modern Language Journal 96(2). 190-208. https://doi.org/10.1111/j.1540-4781.2011.01232_1.x

Lu, Xiaofei. 2014. Computational methods for corpus annotation and analysis. Dordrecht: Springer. doi: 10.1007/978-94-017-8645-4

Menn, Lise. 2017. Psycholinguistics: Introduction and applications. San Diego: Plural Publishing.

Miestamo, Matti. 2006. On the complexity of standard negation. SKY Journal of Linguistics A Man of Measure: Festschrift in Honour of Fred Karlsson on his 60th Birthday 19. 345-356.

Mori, Yoshiko. 1999. Epistemological beliefs and language learning beliefs: What do language learners believe about their learning? Language Learning 49(3). 377-415. https://doi.org/10.1111/0023-8333.00094

Nichols, Johanna. 2009. Linguistic complexity: A comprehensive definition and survey. In Sampson, Geoffrey \& Gil, David \& Trudgill, Peter (eds.), Language Complexity as an Evolving Variable, 110-125. Oxford: Oxford University Press.

Oxford, L. Rebecca. 1990. Language learning strategies: What every teacher should know. Boston: Heinle and Heinle.

Oxford, L. Rebecca. 1999. Relationships between second language learning strategies and language proficiency in the context of learner autonomy and self-regulation. Revista Canaria de Estudios Ingleses 38. 109-126.

Oxford, L. Rebecca. 2013. Teaching and researching language learning strategies. New York: Routledge. 
Pyun, Danielle Ooyoung \& Kim, Jung Sup \& Cho, Hyun Yong \& Lee, Jung Hee. 2014. Impact of affective variables on Korean as a foreign language learners' oral achievement. System 47. 53-63. https://doi.org/10.1016/j.system.2014.09.017

Schommer, Marlene. 1990. Effects of beliefs about the nature of knowledge on comprehension. Journal of Educational Psychology 82. 498-504. http://dx.doi.org/10.1037/0022-0663.82.3.498

Tanaka, Koichi \& Ellis, Rod. 2003. Study-abroad, language proficiency, and learner beliefs about language learning. JALT Journal 25(1). 63-85.

Wolfe-Quintero, Kate \& Inagaki, Shunji \& Kim, Hae-Young. 1998. Second language development in writing: Measures of fluency, accuracy, and complexity. Manoa: University of Hawai'i.

Yuen, Cheung Oi Gary. 2002. Secondary students' English language learning beliefs and oral proficiency: A Hong Kong case study. Unpublished MA thesis. Hong Kong: The University of Hong Kong.

Zhong, Qunyan Maggie. 2013. Learner beliefs and learner autonomy: A case study of two Chinese migrant learners in New Zealand. In May, Stephen (ed.), LED2011: Refereed conference proceedings of the 3rd International Conference on Language, Education and Diversity, 1-11. Auckland: The University of Auckland.

\section{Author's address:}

International University of Sarajevo

Hrasnička 15, Sarajevo

E-mail: ekovacevic@ius.edu.ba

\section{ODNOS IZMEĐU MJERNIH JEDINICA LEKSIČKE SLOŽENOSTI I VJEROVANJA O UČENJU STRANOG JEZIKA}

Iako se odnos između jezičnog umijeća i vjerovanja o učenju općenito opisuje kao slab i neizravan, postoje empirijski dokazi da je veza između mjernih jedinica sintaktičke složenosti i vjerovanja o učenju jezika statistički opipljiva. Budući da je sintaktička složenost samo jedan od podsustava jezične složenosti, potrebno je ispitati jesu li i ostali podsustavi u statistički mjerljivom odnosu s takvim vjerovanjima. U ovoj se studiji istražuje veza između 25 indeksa leksičke složenosti (Lu 2012; 2014) i četiri podljestvice vjerovanja o učenju jezika izvedene iz instrumenta Vjerovanja o učenju jezika (The Beliefs about Language Learning Inventory-BALLI 2.0, Horwitz 2013; Kovačević 2017). Tijekom tri semestra (zimski semestar akademske godine 2014./2015., te ljetni i zimski semestar akademske godine 2015./2016.) prikupljen je uzorak eseja 152 studenta prve godine preddiplomskih programa na Međunarodnom sveučilištu u Sarajevu. Rezultati pokazuju 15 


\section{Ervin Kovačević:}

The relationship between lexical complexity measures and language learning beliefs

statistički značajnih koeficijenata korelacije između 14 indeksa leksičke složenosti i tri podljestvice BALLI 2.0. Na temelju rezultata može se zaključiti da je veza između indeksa leksičke složenosti i vjerovanja o učenju stranog jezika statistički mjerljiva. Na temelju rezultata analize može se izvesti i zaključak da konstrukt leksičke složenosti predstavlja koristan okvir za proučavanje načina na koji, i opsega u kojemu se individualne razlike manifestiraju u uporabi stranog jezika.

Ključne riječi: uvjerenja o učenju jezika; složenost; korelacija; BALLI; korpus. 